\title{
Prevention of age-related macular degeneration
}

\author{
Ian Yat Hin Wong • Simon Chi Yan Koo • \\ Clement Wai Nang Chan
}

Received: 15 January 2010/Accepted: 4 September 2010/Published online: 23 September 2010

(C) The Author(s) 2010. This article is published with open access at Springerlink.com

\begin{abstract}
Age-related macular degeneration (AMD) is one of the leading causes of blindness in the developed world. Although effective treatment modalities such as anti-VEGF treatment have been developed for neovascular AMD, there is still no effective treatment for geographical atrophy, and therefore the most cost-effective management of AMD is to start with prevention. This review looks at current evidence on preventive measures targeted at AMD. Modalities reviewed include (1) nutritional supplements such as the Age-Related Eye Disease Study (AREDS) formula, lutein and zeaxanthin, omega-3 fatty acid, and berry extracts, (2) lifestyle modifications, including smoking and body-mass-index, and (3) filtering sunlight, i.e. sunglasses and blue-blocking intraocular lenses. In summary, the only proven effective preventive measures are stopping smoking and the AREDS formula.
\end{abstract}

Keywords AREDS - Age-related macular degeneration - AMD · Vitamin E - Beta-carotene . Neovascular AMD · Yellow IOL · Sunlight filtration · Prevention

I. Y. H. Wong ( $\bowtie)$

Eye Institute, University of Hong Kong, Hong Kong,

Hong Kong

e-mail: ianyhwong@gmail.com

S. C. Y. Koo - C. W. N. Chan

Tung Wah Eastern Hospital, Hong Kong, Hong Kong

\section{Introduction}

Age-related macular degeneration (AMD) is one of the leading causes of blindness in developed countries [1-3]; currently $11.5 \%$ of the population in the United States is affected [1]. The exact pathogenesis of AMD remains unknown [4], but one of the main components is thought to be oxidative stress $[5,6]$ : the retina, because of its high oxygen concentration and intense light exposure, is susceptible to damage by oxidative stress [6]. Early stages of AMD can be asymptomatic but can cause severe impairment of central vision in late stages. Details of the most up-todate classification of AMD are given in Table 1. There have been some promising new treatments in recent years since the emergence of anti-vascular endothelial growth factor (anti-VEGF) agents, and numerous pivotal studies have proven their effectiveness in controlling neovascular AMD [7]. However, at the moment, costs for these drugs are high and patients may have to undergo multiple injections.

Taking in consideration the ever-growing population, the incidence of AMD will only increase. In the United States alone, it is thought that the incidence may double in the next 20 years [1], and so will the resources and effort spent in the area. Even if anti-VEGF agents are made cheaper and more available, more and more patients will have to rely on them, and as a result the burden on the healthcare system will be increased [8]. It may be more economical to tackle AMD with prevention. Studies done on AMD prevention usually 
Table 1 Categorization of age-related macular degeneration (AMD) according to the Age-Related Eye Disease Study (AREDS) guidelines

\begin{tabular}{|c|c|c|c|}
\hline & Brief description & Clinical features & Visual acuity \\
\hline Category 1 & Free of AMD in both eyes & $<5$ small drusen in one or both eyes & $20 / 32$ or better in both eyes \\
\hline Category 2 & $\begin{array}{l}\text { Mild to borderline AMD } \\
\text { in one or both eyes }\end{array}$ & $\begin{array}{l}\text { Multiple small or intermediate drusen in one } \\
\text { or both eyes } \\
\text { Pigment abnormalities in one or both eyes }\end{array}$ & $20 / 32$ or better in both eyes \\
\hline Category 3 & $\begin{array}{l}\text { Absence of advanced AMD } \\
\text { in both eyes }\end{array}$ & $\begin{array}{l}\text { Intermediate or large drusen } \\
\text { Geographical atrophy } \\
\text { Features not involving central macular }\end{array}$ & $20 / 32$ or better in better eye \\
\hline Category 4 & Advanced AMD in one eye & $\begin{array}{l}\text { Advanced AMD or geographical atrophy } \\
\text { in worse eye } \\
\text { No such features in better eye }\end{array}$ & $20 / 32$ or better in better eye \\
\hline
\end{tabular}

Key: Small drusen, $<63 \mu \mathrm{m}$ in diameter (disc diameter around $1500 \mu \mathrm{m}$ ); intermediate drusen, 63-124 $\mu \mathrm{m}$ in diameter; large drusen, $>125 \mu \mathrm{m}$ in diameter; pigment abnormalities refer to either hyperpigmentation or depigmentation

fall into one of three areas: (1) nutritional supplements, (2) lifestyle modifications, (3) filtering sunlight. It is vital that ophthalmologists and general practitioners be aware of the latest and updated evidence. In this article we hope to provide an overview of current opinions on the prevention of AMD.

\section{Methods}

An evidence-based approach was adopted in the review process. The literature up to December 2009 was searched for keywords 'age-related macular degeneration', 'macular', 'AMD', 'antioxidants', 'mineral supplements', 'dietary supplements', and 'prevention'. We used the databases Medline, The Cochrane Library, Embase.com, Web of Knowledge, and Google Scholar. The search was limited to studies in human subjects, in English. Strength of evidence and rating of recommendation were assessed according to the method described previously [9], and are summarized in Table 3.

\section{Evidence synthesis}

Nutritional supplements

Most studies focused on four types of supplements:

1. AREDS or AREDS-like formulas,

2. Lutein and zeaxanthin,
3. Omega-3 fatty acids, 4. Berry extracts.

\section{AREDS or AREDS-like formulas}

The Age-Related Eye Disease Study (AREDS) was designed to investigate whether active treatment with supplements such as vitamins and minerals can reduce the risk of advanced AMD. The main components of the formula were vitamin A (as beta-carotene), vitamin $\mathrm{C}$, vitamin $\mathrm{E}$, and zinc. These ingredients were thought to exert a protective effect on retinal cells by counteracting oxidative stresses [10-15]. The formula was a type of active treatment and therefore the dosages of ingredients were much higher than the Dietary Reference Intake (DRI), which is a system of nutrition recommendations from the Institute of Medicine of the USA National Academy [16]. For instance, the amount of vitamin $\mathrm{C}$ included in the AREDS formula was $500 \mathrm{mg}$ per day, whereas the DRI for an adult is only $90 \mathrm{mg}$ per day (a medium-sized orange contains around $70 \mathrm{mg}$ of vitamin $\mathrm{C}$, and therefore one has to eat almost seven or eight oranges to obtain $500 \mathrm{mg}$ of vitamin C). A detailed comparison of nutrient contents between the AREDS formula and common fruits is given in Table 2.

Subjects were categorized initially according to the suggested grading system [17], and then were asked to take either the supplements or placebo on twice a day. The progress of 3,640 subjects was 
Table 2 Dosages of the Age-Related Eye Disease Study (AREDS) type formulas compared with common fruit items

\begin{tabular}{llllllllll}
\hline Nutrient & AREDS [17] & DRI $^{\mathrm{a}}$ & Orange $^{\mathrm{b}}$ & Apple $^{\mathrm{b}}$ & Blueberry $^{\mathrm{b}}$ & Banana $^{\mathrm{b}}$ & Mango $^{\mathrm{b}}$ & Strawberry $^{\mathrm{b}}$ & Watermelon $^{\mathrm{b}}$ \\
\hline Vitamin $^{\mathrm{c}}(\mathrm{IU})$ & 5000 & 3000 & 225 & 54 & 22 & 64 & 765 & 18 & 569 \\
Vitamin C (mg) & 500 & 90 & 53.2 & 4.6 & 0.7 & 8.7 & 27.7 & 13.7 & 8.1 \\
Vitamin E (mg) & 400 & 15 & 0.1 & 0.18 & 0.23 & 0.10 & 1.12 & 0.1 & 0.05 \\
Zinc (mg) & 80 & 11 & 0.07 & 0.04 & 0.1 & 0.15 & 0.04 & 0.06 & 0.1 \\
Copper (mg) & 2 & 0.9 & 0.045 & 0.027 & 0.12 & 0.078 & 0.11 & 0.03 & 0.042 \\
Lutein/zeaxanthin $(\mu \mathrm{g})$ & None & No data & 129 & 29 & 33 & 22 & 0 & 9 & 8 \\
\hline
\end{tabular}

${ }^{a}$ Dietary Reference Intakes from the Institute of Medicine [16]

b Nutrient contents of common fruit items are measured per $100 \mathrm{~g}$

c Vitamin A as beta-carotene

monitored for an average of 6.3 years. In essence, the results showed a $25 \%$ reduction in risk of progression to advanced AMD if recommended doses of antioxidants and zinc were taken daily. However, this was seen in category 3 or 4 patients only, probably because of the higher natural risk of progression to advanced AMD. Results were not significant for category 2 or 1, i.e. those with small drusen only (the 5 -year risk of progression to advanced AMD in category 2 was only $1.3 \%$ and in category $1<1 \%$ ).

However, in the USA $80 \%$ of people over age 70 fall into category 1 or 2 , and hence most people would probably not benefit from the AREDS formula. Therefore it was only recommended to high-risk patients (i.e. category 3 or 4). For low risk patients (i.e. category 1 or 2 ), recommendation was deferred until indicated [17].

Potential risks of the AREDS formula include kidney stones from vitamin $\mathrm{C}$; fatigue, muscle weakness, decreased thyroid function, and increased hemorrhagic stroke risk from vitamin E; increased lung cancer risk in smokers and yellow discoloration of skin from beta-carotene; and anemia, decreased serum high-density lipoprotein cholesterol, and stomach upset from zinc [18]. Despite numerous potential side effects, the only documented statistically significant ones were increased genitourinary symptoms, increased self-reported anemia, and yellow discoloration of skin. Although there was an increase in selfreported anemia, no significant change in blood hematocrit level was found. Smokers were discouraged from taking pills containing beta-carotene, so an increased risk of lung cancer with beta-carotene was not addressed in the AREDS, but it has already been established in two other trials $[19,20]$. Nevertheless, the few side effects were minor and the formula was otherwise considered safe. In any case, patients should always be informed of the risks and when significant contraindications exist (smoking, vascular diseases, hyperlipidemia, risk of hemorrhage, etc.), they should be discouraged from taking the formula.

Instead of an active supplementation formula, some have proposed an enriched diet alone. The Rotterdam Study investigated the effect of a vitaminand mineral-rich diet alone in the prevention of AMD [21]. In comparison to the AREDS, no active interventions were given. Baseline dietary content was assessed, and followed up for possible development of AMD. The study found that an above-median intake of vitamin $\mathrm{C}$ and $\mathrm{E}$, beta-carotene, and zinc was associated with a striking $35 \%$ decrease in incident AMD [21]. They concluded that such a diet should be recommended to those with early signs of AMD or those with a strong family history.

A recent meta-analysis carried out by the Cochrane Collaboration reviewed the evidence and concluded that both these recommendations were sound but patients should nevertheless be warned of potential harmful effects, particularly those who smoke or who have vascular diseases [22]. Since patients take these pills on a prophylactic basis, it is undesirable to have complications arising.

\section{Lutein and zeaxanthin}

Also of great interest is the antioxidant balance among macular pigments, mainly lutein and its stereo-isomer, zeaxanthin. These carotenoids exist 
in high concentrations in the macula, hence its yellowish color. In vitro studies have shown that both protect the retina from oxidative stress [23]. These carotenoids act in biological systems as (1) an important structural molecule in cell membranes, (2) a short-wavelength light filter, (3) a keeper of the redox balance, and (4) a modulator in signal transduction pathways $[24,25]$. However, the human body is not capable of lutein synthesis; it can only be obtained from diet. Hence, supplementing the body with lutein may offer protection against AMD. However, these were not included in the AREDS because neither of the two substances was ready for manufacturing as a research formula [18].

The Carotenoids in Age-Related Eye Disease Study (CAREDS) followed 1,787 American women aged 50-79 for 4-7 years [26]. Subjects were divided according to their average intake of dietary lutein and zeaxanthin, but here were no statistical differences between the amount of lutein and zeaxanthin they took and the risk of development of AMD.

Conversely, two other studies were in favor of the hypothesis. The cohort Pathologies Oculaires Liées à l'Age (POLA) measured actual plasma carotenoids levels from 899 subjects and correlated them with risk of AMD. A striking reduction in risk was found in those with a high plasma level: the odds ratios were 0.31 and 0.07 for lutein and zeaxanthin, respectively [27]. This was in agreement with another similar study in the UK, where a high plasma zeaxanthin was associated with a $50 \%$ reduction in risk of AMD [28].

The US Food and Drug Administration (FDA) denied a link between the carotenoids and AMD protection after reviewing some interventional and observational randomized studies [29]. In view of the contradicting results, the National Eye Institute (Bethesda, Maryland, USA) launched the AgeRelated Eye Disease Study 2 (AREDS2) in autumn of 2006, hoping to answer this question. As well as carotenoids, it also studies omega-3 [30, 31]. It also modifies the original formula by eliminating betacarotene, which increases the risk of lung cancer in smokers. The proposed study end time is late 2012. In the meantime, no evidence-based conclusion can be reached.

Although not yet proven for benefits, many manufacturers have been including lutein and zeaxanthin in their supplements, many of which are available over the counter. In 2006, the Council for Responsible Nutrition (CRN) in Washington DC reviewed the risk profile of lutein and concluded that the only documented side effect is yellow discoloration of skin, characterized by high dermal caroteinoid levels. This condition is reversible and benign and there were no other adverse events [32]. The CRN also suggested a daily lutein upper level of supplementation (ULS) of $20 \mathrm{mg}$. Lutein and zeaxanthin carry potential benefits, and have minimal side effects. For those who are keen and are at risk of AMD, they may offer some protection.

\section{Omega-3 fatty acids}

The role of omega- 3 fatty acids in reducing the incidence of cardiovascular diseases and strokes has been well established [33]. For instance, the American Heart Association recommends the intake of omega-3 fatty acids in the form of either fish or fish oil capsule supplements for cardiovascular benefits [34]. Recently, its role in AMD has also been investigated. Docosahexaenoic acid (DHA) is a type of omega-3 fatty acid present in high concentration in the photoreceptor segment of the retina. It is constantly being shed and reformed in the normal visual cycle, and has been shown to reduce inflammation and regulate autoimmune responses [35-40], which in turn prevents AMD. Hodge et al. carried out a meta-analysis and concluded that evidence so far was inconsistent and not randomized [41]. Larger randomized controlled trials are needed before conclusions can be drawn.

More recently, the US Twin Study of Age-Related Macular Degeneration (USTS) investigated the relationship among 681 twins, and found that fish consumption and omega- 3 fatty acid intake reduced the risk of AMD [42], by an estimated $22 \%$ if omega3 was high. However, the study was not randomized and hence its impact is limited.

Because of the potential antithrombotic effect of fish oil, the risk of hemorrhagic stroke is potentially increased [43]. Clinical studies have demonstrated that even with concurrent administration of agents like warfarin and aspirin, a high dose of fish oil does not significantly increase the risk of bleeding [44-46]. Another safety concern is environmental contaminants such as mercury, which is commonly 
found in fish; high consumption of fish or fish oil capsules may pose potential health threats. The FDA issued an advisory statement recommending that pregnant women, breast-feeding mothers and children avoid eating certain types of seafood high in mercury [47]. The risk is still low and is limited to certain types of fish such as golden bass, shark, king mackerel, and swordfish [33]. Fish oil supplements are generally considered safe because most industrial purification processes eliminate these toxins [48, 49].

The risk of taking omega-3 fatty acids either from dietary fish or fish oil supplements is low, and the potential benefits outweigh the risks. With the proven cardiovascular benefits, consumption of fish or fish oil supplements remains a reasonable and safe recommendation.

\section{Berry extracts}

The interest in berry extracts grew from their antioxidant properties. Probably the most notable member of the berry family is blueberry, which ranked first in antioxidant properties among 100 common food items published by the United States Department of Agriculture assays [50]. As far as ophthalmology is concerned, its antioxidant strength helps reduce risk of $\mathrm{AMD}$, and improves night vision. Many berry extract products claim to protect eyes from AMD. Another berry, wolfberry, better known as 'goji berry', which has been long used in Traditional Chinese Medicine (TCM), is also known for its eye-protecting properties [51].

Anthocyanin is commonly present, and in plant studies it was found to absorb blue-green light and protect cells from light stress [52]. Other laboratory studies have shown that it can theoretically protect eyes from degenerative diseases like AMD [53-55]. Others also suggested anti-angiogenic and anti-cancer properties in anthocyanin [53, 56, 57]. However, at the moment evidence is limited to the laboratory level. The precise dosage and frequency remains uncertain, and potential toxicity and long-term side effects still require exploration.

Currently there are no legal requirements for quality control of these extracts. Most of these products need not disclose their exact content and production method. At the moment, berry extracts should not be recommended.
Lifestyle modifications

\section{Smoking cessation}

The only established causative factor for AMD is smoking, which has been linked to increased oxidative stress, platelet aggregation, higher fibrinogen level, and reduced plasma high-density lipoprotein and antioxidant levels [58-60].

In AREDS Report No. 19, subjects who smoke were found to have a higher risk of progression to advanced AMD. For 10 pack-years or higher smokers, the odds ratio for advanced AMD was 1.55 [61]. Results of the US Twin Study showed that current smokers had a 1.9-fold increased risk of having AMD, and ex-smokers still had a 1.7-fold increased risk [42]. If smokers take supplements containing beta-carotene, the risk of lung cancer is further increased $[19,20]$. All smokers should be advised to stop.

\section{Body mass index (BMI)}

In the AREDS, a higher risk of the geographical atrophy type of AMD was seen in subjects with higher BMI [19, 20, 61]. The odds ratio was 1.93 in obese individuals (obese BMI $\geq 30 \mathrm{~kg} / \mathrm{m}$ [2], normal BMI $18.5-24.9 \mathrm{~kg} / \mathrm{m}$ [2]). Another study by Seddon et al. also produced similar results [62].

Reducing light exposure

\section{Sunglasses}

Some studies have suggested that sunlight exposure may contribute to AMD [63-73]. The Beaver Dam Eye Study (BDES) was a population-based cohort study measuring the amount of sunlight exposure and incidence of AMD in 2,764 subjects over a 10-year period [74]. The BDES found that extended sunlight exposure was associated with higher incidence of early AMD. However, the protective effect of sunglasses was only marginal, and the data were reported on a subjective basis.

More supporting evidence comes from reports on the incidence of AMD after cataract surgery and intraocular lens (IOL) implantation [75-77]. Human crystalline lens turns yellow with age and has been proven to protect the retina from harmful ultraviolet 
(UV) blue or blue-green phototoxicity [78, 79]. When the crystalline lens is removed during surgery, the implanted IOL does not provide equivalent theoretical protection in vivo [79]. For those who have had cataract surgery, wearing sunglasses in outdoor areas may provide protection in this regard.

\section{Spectral filtering IOLs}

A theoretical link has been proposed between phototoxicity and cataract extraction [80]. Most modernday IOLs mimic the crystalline lens in filtering the harmful UV spectrum of 300-400 nm [78, 81]. The human crystalline lens turns yellow with age, thereby blocking blue light (400-500 nm), while IOLs tend to be transparent [82].

In the Chesapeake Bay Watermen Study, a significant correlation between blue or visible light exposure and AMD was found [68]. In fact, after cataract extraction, blue light exposure is greater than at any other point in life [83].

Among the blue-light blocking properties of modern IOLs (better known as 'Yellow IOLs'), transmittance mimics that of a human adult crystalline lens. One example is the AcrySof ${ }^{\circledR}$ Natural IOL by Alcon (Fort Worth, Texas, USA), which partially attenuates violet light (400-440 nm) [84], and blocks 50\% of blue light at $450 \mathrm{~nm}$ and $25 \%$ at $480 \mathrm{~nm}$ [85]. In contrast, conventional transparent IOLs transmit $90 \%$ of light $>400 \mathrm{~nm}$ [82]. Therefore these yellow IOLs may theoretically protect the macula from phototoxicity.

Concerns have been raised that these yellow IOLs attenuate visual performances under scotopic conditions (defined as lighting levels as experienced on a moonless night with only starlight), because blue light, which is more informative in this environment, is being partially filtered [82]. Furthermore, some raised the issue of possible differences in color perception. For instance, driving at night is considered a mesopic task [86], which refers to lighting conditions under a quarter of a full moon [87]. Even under scotopic conditions, contrast sensitivity is greatest around the $507 \mathrm{~nm}$ wavelength, and the AcrySof Natural IOL transmits $85 \%$ of light at this wavelength, as compared to $90 \%$ with conventional transparent IOLs, and only around $60 \%$ in a young

Table 3 Summary of recommendations

\begin{tabular}{|c|c|c|c|c|}
\hline Category & Study & Recommendation & $\begin{array}{l}\text { Strength of } \\
\text { evidence }^{\mathrm{a}}\end{array}$ & $\begin{array}{l}\text { Rating of } \\
\text { recommendation }^{\mathrm{a}}\end{array}$ \\
\hline \multicolumn{5}{|l|}{ Nutritional supplements } \\
\hline \multirow[t]{2}{*}{ AREDS formula } & AREDS & Regular intake may reduce risk of neovascular AMD & $\mathrm{I}$ & B \\
\hline & Cochrane [22] & Regular intake may reduce risk of neovascular AMD & I & A \\
\hline \multirow[t]{4}{*}{ Lutein and zeaxanthin } & AREDS2 & Not yet available & $\mathrm{n} / \mathrm{a}$ & $\mathrm{n} / \mathrm{a}$ \\
\hline & CAREDS & No difference & II & $\mathrm{C}$ \\
\hline & POLA & Higher lutein and zeaxanthin reduced risk of AMD & II & $\mathrm{C}$ \\
\hline & Gale et al. [28] & Higher lutein and zeaxanthin reduced risk of AMD & II & $\mathrm{C}$ \\
\hline \multirow[t]{2}{*}{ Omega-3 } & AREDS2 & Not yet available & $\mathrm{n} / \mathrm{a}$ & $\mathrm{n} / \mathrm{a}$ \\
\hline & USTS & Higher omega-3 intake reduced risk of AMD & II & $\mathrm{C}$ \\
\hline Berry extracts & None & $\mathrm{n} / \mathrm{a}$ & $\mathrm{n} / \mathrm{a}$ & $\mathrm{n} / \mathrm{a}$ \\
\hline \multicolumn{5}{|l|}{ Life style } \\
\hline \multirow[t]{2}{*}{ Smoking } & AREDS & Smokers had higher risk of AMD & $\mathrm{I}$ & B \\
\hline & USTS & Smokers had higher risk of AMD & II & $\mathrm{C}$ \\
\hline BMI & AREDS & Higher BMI was associated with higher risk of AMD & I & $\mathrm{B}$ \\
\hline \multicolumn{5}{|l|}{ Sunlight filtering } \\
\hline Sunglasses & BDES & Benefit of sunglasses use against AMD marginal & II & $\mathrm{C}$ \\
\hline Yellow IOLs & None & $\mathrm{n} / \mathrm{a}$ & $\mathrm{n} / \mathrm{a}$ & $\mathrm{n} / \mathrm{a}$ \\
\hline
\end{tabular}

n/a data not available, AREDS Age-Related Eye Disease Study [17], AREDS2 Age-Related Eye Disease Study 2 [31], CAREDS Carotenoids in Age-Related Eye Disease Study [26], POLA 'Pathologies Oculaires Liées à l'Age' study [27], USTS United States Twins Study [42], BDES Beaver Dam Eye Study [66]

a Strength of evidence and rating of recommendation rated according to method described previously [9] 
adult natural crystalline lens [78]. In fact, some studies even reported increased contrast sensitivity with the yellow IOLs [88-90].

Cionni used the Farnsworth 100-Hue test in subjects who had undergone bilateral yellow IOL implantation, and found no significant changes in terms of color perception [91]. Comparison was also made with those who had a yellow IOL implanted in one eye, and a transparent IOL in the other, and found no significant alternations [92]. Hence for most patients a yellow IOL may offer theoretical protection from AMD.

\section{Summary and conclusions}

A systematic review of evidence on the prevention of age-related macular degeneration was made. A summary of recommendations is given in Table 3. The AREDS formula remains the only A-rated recommendation so far. When dealing with patients, it is the responsibility of the practitioner to fully explain the nature of supplements and potential side effects from long-term regular intake, especially the increased risk of lung cancer in smokers. Any misconceptions should be addressed and rectified. It is also necessary to remind patients that even when taking the AREDS formula, AMD can still occur. Patients should be taught self-monitoring methods and undergo regular fundal examinations by qualified ophthalmologists. The importance of this cannot be over-emphasized.

Open Access This article is distributed under the terms of the Creative Commons Attribution Noncommercial License which permits any noncommercial use, distribution, and reproduction in any medium, provided the original author(s) and source are credited.

\section{References}

1. Eye Disease Prevalence Research Group (2004) Prevalence of age-related macular degeneration in the United States. Arch Ophthalmol 122:564-572

2. Evans J, Wormald R (1996) Is the incidence of registrable age-related macular degeneration increasing? $\mathrm{Br} \mathrm{J}$ Ophthalmol 80:9-14

3. VanNewkirk M, Weih LM, McCarty CA, Taylor HR (2001) Cause-specific prevalence of bilateral visual impairment in Victoria, Australia: the visual impairment project. Ophthalmology 108:960-967
4. Bressler NM (2000) Age related macular degeneration. New hope for a common problem comes from photodynamic therapy. BMJ 321:1425-1427

5. Zarbin MA (2004) Current concepts in the pathogenesis of age-related macular degeneration. Arch Ophthalmol 122: 598-614

6. Beatty S, Koh H, Phil M, Henson D, Boulton M (2000) The role of oxidative stress in the pathogenesis of age-related macular degeneration. Surv Ophthalmol 45:115-134

7. Rosenfeld PJ, Brown DM, Heier JS et al (2006) Ranibizumab for neovascular age-related macular degeneration. N Engl J Med 355:1419-1431

8. Gupta OP, Brown GC, Brown MM (2007) Age-related macular degeneration: the costs to society and the patient. Curr Opin Ophthalmol 18:201-205

9. Minckler D (2000) Evidence-based ophthalmology series and content-based continuing medical education for the journal. Ophthalmology 107:9-10

10. Seddon JM, Ajani UA, Sperduto RD, Eye Disease CaseControl Study Group et al (1994) Dietary carotenoids, vitamins $\mathrm{A}, \mathrm{C}$, and $\mathrm{E}$, and advanced age-related macular degeneration. JAMA 272:1413-1420

11. Snellen EL, Verbeek AL, Van Den Hoogen GW, Cruysberg JR, Hoyng CB (2002) Neovascular age-related macular degeneration and its relationship to antioxidant intake. Acta Ophthalmol Scand 80:368-371

12. Goldberg J, Flowerdew G, Smith E, Brody JA, Tso MO (1988) Factors associated with age-related macular degeneration: an analysis of data from the first National Health and Nutrition Examination Survey. Am J Epidemiol 128:700-710

13. VandenLangenberg GM, Mares-Perlman JA, Klein R, Klein BE, Brady WE, Palta M (1998) Associations between antioxidant and zinc intake and the 5-year incidence of early age-related maculopathy in the Beaver Dam Eye Study. Am J Epidemiol 148:204-214

14. Newsome DA, Swartz M, Leone MC, Elston RC, Miller E (1988) Oral zinc in macular degeneration. Arch Ophthalmol 106:192-198

15. Moriarty-Craige SE, Ha K-N et al (2007) Effects of longterm zinc supplementation on plasma thiol metabolites and redox status in patients with age-related macular degeneration. Am J Ophthalmol 143:206-211

16. Dietary Reference Intakes, Institute of Medicine of the National Academies website. http://www.iom.edu/CMS/ 3788/4574.aspx. Accessed 15 December 2007

17. The Age-Related Eye Disease Study Research Group (2001) A randomized, placebo-controlled, clinical trial of high-dose supplementation with vitamins $\mathrm{C}$ and $\mathrm{E}$, beta carotene, and zinc for age-related macular degeneration and vision loss. AREDS Report No. 8. Arch Ophthalmol 119:1417-1436

18. Klein R, Peto T, Bird A et al (2004) The epidemiology of age-related macular degeneration. Am J Ophthalmol 137:486-495

19. Omenn GS, Goodman GE, Thornquist MD et al (1996) Effects of a combination of beta carotene and vitamin A on lung cancer and cardiovascular disease. N Engl J Med 334:1150-1155

20. The Alpha-Tocopherol Beta Carotene Cancer Prevention Study Group (1994) The effect of vitamin E and beta 
carotene on the incidence of lung cancer and other cancers in male smokers. N Engl J Med 330:1029-1035

21. van Leeuwen R, Boekhoorn S, Vingerling JR, Witteman JC, Klaver CC, Hofman A, de Jong PT (2005) Dietary intake of antioxidants and risk of age-related macular degeneration. JAMA 294:3101-3107

22. Evans JR (2006) Antioxidant vitamin and mineral supplements for slowing the progression of age related macular degeneration. Cochrane Database Syst Rev (2):CD000 254

23. Sujak A, Gabrielska J, Grudzinski W, Borc R et al (1999) Lutein and zeaxanthin as protectors of lipid membranes against oxidative damage: the structural aspects. Arch Biochem Biophys 371:301-307

24. Rosenthal JM, Kim J, Monastario F et al (2006) Doseranging study of lutein supplementation in persons aged 60 years or older. Invest Ophthalmol Vis Sci 47:5227-5233

25. Whitehead AJ, Mares JA, Danis RP (2006) Macular pigment: a review of current knowledge. Arch Ophthalmol 124:1038-1045

26. Moeller SM, Parekh N, Tinker L, CAREDS Research Study Group et al (2006) Associations between intermediate age-related macular degeneration and lutein and zeaxanthin in the Carotenoids in Age-Related Eye Disease Study (CAREDS): ancillary study of the Women's Health Initiative. Arch Ophthalmol 124:1151-1162

27. Delcourt C, Carrière I, Delage $M$, Barberger-Gateau $P$, Schalch W, the POLA Study Group (2006) Plasma lutein and zeaxanthin and other carotenoids as modifiable risk factors for age-related maculopathy and cataract: the POLA study. Invest Ophthalmol Vis Sci 47:2329-2335

28. Gale CR, Hall NF, Phillips DI, Martyn CN (2003) Lutein and zeaxanthin status and risk of age-related macular degeneration. Invest Ophthalmol Vis Sci 44:2461-2465

29. Trumbo PR, Ellwood KC (2006) Lutein and zeaxanthin intakes and risk of age-related macular degeneration and cataracts: an evaluation using the Food and Drug Administration's evidence-based review system for health claims. Am J Clin Nutr 84:971-974

30. Coleman H, Chew E (2007) Nutritional supplementation in age-related macular degeneration. Curr Opinion Ophthalmol 18:220-223

31. AREDS2 website. http://www.nei.nih.gov/neitrials/view StudyWeb.aspx?id=120. Accessed 15 December 2009

32. Shao A, Hathcock JN (2006) Risk assessment for the carotenoids lutein and lycopene. Regul Toxicol Pharmacol 45:289-298

33. Mozaffarian D, Rimm EB (2006) Fish intake, contaminants, and human health: evaluating the risks and the benefits. JAMA 296:1885-1899

34. Bang HO, Dyerberg J (1980) Lipid metabolism and ischaemic heart disease in Greenland Eskimos. In: Draper $\mathrm{H}$ (ed) Advances in nutrition research. Plenum Press, New York, pp 1-22

35. Seddon JM, Gensler G, Milton RC, Klein ML, Rifai N (2004) Association between C-reactive protein and agerelated macular degeneration. JAMA 291:704-710

36. Edwards AO, Ritter R, Abel KJ, Manning A, Panhuysen C, Farrer LA (2005) Complement factor $\mathrm{H}$ polymorphism and age-related macular degeneration. Science 308:421-424
37. Klein RJ, Zeiss C, Chew E et al (2005) Complement factor $\mathrm{H}$ polymorphism in age-related macular degeneration. Science 308:385-389

38. Hageman GS, Anderson DH, Johnson LV et al (2005) A common haplotype in the complement regulatory gene factor $\mathrm{H}(\mathrm{HF} 1 / \mathrm{CFH})$ predisposes individuals to age-related macular degeneration. Proc Natl Acad Sci USA 102:7227-7232

39. Haines JL, Hauser MA, Schmidt S et al (2005) Complement factor $\mathrm{H}$ variant increases the risk of age-related macular degeneration. Science 308:419-421

40. Horrocks LA, Yeo YK (1999) Health benefits of docosahexaenoic acid (DHA). Pharmacol Res 40:211-225

41. Hodge WG, Schachter HM, Barnes D et al (2006) Efficacy of $\omega$-3 fatty acids in preventing age-related macular degeneration: a systematic review. Ophthalmology 113: 1165-1173

42. Seddon JM, George S, Rosner B (2006) Cigarette smoking, fish consumption, omega-3 fatty acid intake, and associations with age-related macular degeneration: the US Twin Study of age-related macular degeneration. Arch Ophthalmol 124:995-1001

43. Carroll DN, Roth MT (2002) Evidence for the cardioprotective effects of omega-3 fatty acids. Ann Pharmacother 36:1950-1956

44. Eritsland J, Arnesen H, Gronseth K, Fjeld NB, Abdelnoor M (1996) Effect of dietary supplementation with n-3 fatty acids on coronary artery bypass graft patency. Am J Cardiol 77:31-36

45. Leaf A, Jorgensen MB, Jacobs AK et al (1994) Do fish oils prevent restenosis after coronary angioplasty? Circulation 90:2248-2257

46. Bender NK, Kraynak MA, Chiquette E, Linn WD, Clark GM, Bussey HI (1998) Effects of marine fish oils on the anticoagulation status of patients receiving chronic warfarin therapy. J Thromb Thrombolysis 5:257-261

47. US Department of Health and Human Services, US Environmental Protection Agency. What you need to know about mercury in fish and shellfish. CFSAN Website. Available at http://www.cfsan.fda.gov/dms/admehg3.html. Accessed 15 December 2007

48. Foran SE, Flood JG, Lewandrowski KB (2003) Measurement of mercury levels in concentrated over-the-counter fish oil preparations: is fish oil healthier than fish? Arch Pathol Lab Med 127:1603-1605

49. Good news! These supplements have omega-3's without contaminants found in fish! But some are better than others. Find out now! [report.] ConsumerLab.com Website. Available at http://www.consumerlab.com/results/omega3. asp. Accessed 15 December 2007

50. Dietary Guidance, National Agricultural Library, United States Department of Agriculture website. http://riley.nal. usda.gov/nal_display/index.php?info_center=4\&tax_level=2 \&tax_subject=256\&topic_id=1342. Accessed 15 December 2007

51. Wang X, Hu S (2001) A review of research actuality on age-related macular degeneration. Yan Ke Xue Bao 17(4):245-251

52. Liakopoulos G et al (2006) The photoprotective role of epidermal anthocyanins and surface pubescence in young 
leaves of grapevine (Vitis vinifera). Ann Bot (Lond) 98(1):257-265

53. Bagchi D, Sen CK, Bagchi M, Atalay M (2004) Antiangiogenic, antioxidant, and anti-carcinogenic properties of a novel anthocyanin-rich berry extract formula. Biochemistry (Mosc) 69(1):75-80; 1 p preceding 75. Review

54. Sadilova E, Carle R, Stintzing FC (2007) Thermal degradation of anthocyanins and its impact on color and in vitro antioxidant capacity. Mol Nutr Food Res 51(12):14611471

55. Bagchi D, Roy S, Patel V et al (2006) Safety and wholebody antioxidant potential of a novel anthocyanin-rich formulation of edible berries. Mol Cell Biochem 281(1-2):197-209

56. Faria A, Oliveira J, Neves P, Gameiro P, Santos-Buelga C, de Freitas V, Mateus N (2005) Antioxidant properties of prepared blueberry (Vaccinium myrtillus) extracts. J Agric Food Chem 53(17):6896-6902

57. Lamy S, Blanchette M, Michaud-Levesque J, Lafleur R, Durocher Y, Moghrabi A, Barrette S, Gingras D, Beliveau R (2006) Delphinidin, a dietary anthocyanidin, inhibits vascular endothelial growth factor receptor-2 phosphorylation. Carcinogenesis 27(5):989-996; Epub 2005 Nov 23

58. Roy S, Khanna S, Alessio HM, Vider J, Bagchi D, Bagchi M, Sen CK (2002) Anti-angiogenic property of edible berries. Free Radic Res 36(9):1023-1031

59. Tomany SC, Wang JJ, van Leeuwen R et al (2004) Risk factors for incident age-related macular degeneration: pooled findings from 3 continents. Ophthalmology 111:1280-1287

60. The health consequences of smoking: a report of the surgeon general, 2005. http://www.cdc.gov/tobacco/sgr/sgr_ 2004/index.htm. Accessed 15 December 2007

61. Age-Related Eye Disease Study Research Group (2005) Risk factors for the incidence of advanced age-related macular degeneration in the Age-Related Eye Disease Study (AREDS): AREDS report No. 19. Ophthalmology 112:533-539

62. Seddon JM, Cote J, Davis N, Rosner B (2003) Progression of age-related macular degeneration: association with body mass index, waist circumference, and waist-hip ratio. Arch Ophthalmol 121:785-792

63. Eye Disease Case-Control Study Group (1992) Risk factors for neovascular age related macular degeneration. Arch Ophthalmol 110:1701-1708

64. Age-Related Eye Disease Study Research Group (2000) Risk factors associated with age-related macular degeneration. Ophthalmology 107:2224-2232

65. Klein R, Clegg L, Cooper LS et al (1999) Prevalence of age-related maculopathy in the Atherosclerosis Risk in Communities Study. Arch Ophthalmol 117:1203-1210

66. Klein R, Klein BEK, Tomany SC, Moss SE (2002) Tenyear incidence of age-related maculopathy and smoking and drinking: the Beaver Dam Eye Study. Am J Epidemiol 156:589-598

67. West SK, Rosenthal FS, Bressler NM et al (1989) Exposure to sunlight and other risk factors for age-related macular degeneration. Arch Ophthalmol 107:875-879

68. Taylor HR, West SK, Munoz MS et al (1992) The longterm effect of visual light to the eye. Arch Ophthalmol 110:99-104
69. Cruickshanks KJ, Klein R, Klein BEK (1993) Sunlight and age-related macular degeneration: the Beaver Dam Eye Study. Arch Ophthalmol 111:514-518

70. Cruickshanks KJ, Klein R, Klein BEK, Nondahl DM (2001) Sunlight and the 5-year incidence of early agerelated maculopathy: the Beaver Dam Eye Study. Arch Ophthalmol 119:246-250

71. Darzins P, Mitchell P, Heller RF (1997) Sun exposure and age-related macular degeneration: an Australian casecontrol study. Ophthalmology 104:770-776

72. Mitchell P, Smith W, Wang JJ (1998) Iris color, skin sun sensitivity, and age-related maculopathy: the Blue Mountains Eye Study. Ophthalmology 105:1359-1363

73. Delcourt C, Carriere I, Ponton-Sanchez A et al (2001) Light exposure and the risk of age-related macular degeneration. Arch Ophthalmol 119:1463-1468

74. Tomany SC, Cruickshanks KJ, Klein R et al (2004) The Beaver Dam Eye Study: sunlight and the 10-year incidence of age-related maculopathy. Arch Ophthalmol 122:750 757

75. Klein R, Klein BE, Wong TY et al (2002) The association of cataract and cataract surgery with the long-term incidence of age-related maculopathy: the Beaver Dam eye study. Arch Ophthalmol 120:1551-1558

76. Wang JJ, Klein R, Smith W et al (2003) Cataract surgery and the 5-year incidence of late-stage age-related maculopathy: pooled findings from the Beaver Dam and Blue Mountains eye studies. Ophthalmology 110:1960-1967

77. Freeman EE, Munoz B, West SK et al (2003) Is there an association between cataract surgery and age-related macular degeneration? Data from three population-based studies. Am J Ophthalmol 135:849-856

78. Boettner EA, Wolter JR (1962) Transmission of the ocular media. Invest Ophthalmol 1:776-783

79. Mainster MA (2006) Violet and blue light blocking intraocular lenses: photoprotection versus photoreception. Br J Ophthalmol 90:784-792

80. Cugati S, Mitchell P, Rochtchina E et al (2006) Cataract surgery and the 10-year incidence of age-related maculopathy: The Blue Mountain Eye Study. Ophthalmology 113:2020-2025

81. Mainster MA (1986) The spectra, classification, and rationale of ultraviolet-protective intraocular lenses. Am J Ophthalmol 102:727-732

82. Braunstein RE, Sparrow JR (2005) A blue-blocking intraocular lens should be used in cataract surgery. Arch Ophthalmol 123:547-549

83. Pollack A, Marcovich A, Bukelman A et al (1996) Agerelated macular degeneration after extracapsular cataract extraction with intraocular lens implantation. Ophthalmology 103:1546-1554

84. Sparrow J, Miller AS, Zhou J (2004) Blue light absorbing intraocular lens and retinal pigment epithelium protection in vivo. J Cat Refract Surg 30:873-878

85. Alcon Laboratories 1 (2003) AcrySof Natural Single-Piece IOL Product Monograph. Alcon Laboratories 1, Fort Worth

86. Mainster MA, Timberlake GT (2003) Why HID headlights bother older drivers. Br J Ophthalmol 87:113-117

87. Marshall J, Greenstein V, Kline D, Owsley C, Werner JS (1986) Optical radiation and the aged eye. In: Waxler M, 
Hitchins VM (eds) Optical radiation and visual health. CRC Press, Boca Raton, pp 43-67

88. de Fez MD, Luque MJ, Viqueira V (2002) Enhancement of contrast sensitivity and losses of chromatic discrimination with tinted lenses. Optom Vis Sci 79:590-597

89. Wolffsohn JS, Cochrane AL, Khoo H, Yoshimitsu Y, Wu S (2000) Contrast is enhanced by yellow lenses because of selective reduction of short-wavelength light. Optom Vis Sci 77:73-81

90. Rabin J, Wiley R (1996) Differences in apparent contrast in yellow and white light. Ophthalmic Physiol Opt 16:6872
91. Cionni RJ (2004) Color perception in patients with UV or blue-light-filtering IOLs. In: Symposium on cataract, IOL and refractive surgery. American Society of Cataract and Refractive Surgery, San Diego. Abstract 337

92. Tjia K (2004) AcrySof Natural SN60 and clear SA60 IOLs: intraindividual comparison. In: Symposium on cataract, IOL and refractive surgery. American Society of Cataract and Refractive Surgery, San Diego. Abstract 426 